\title{
Abnormalities of Autonomic Nervous Control in Human Hypertension
}

\author{
Stevo Julius \\ Division of Hypertension, University of Michigan Medical School. \\ Ann Arbor, MI, USA
}

Summary. The pathophysiology of various stages of hypertension is different. In early hyperkinetic borderline hypertension, the sympathetic drive to the heart and blood vessels is increased while the parasympathetic cardiac inhibition is decreased. The elevated cardiac output, vascular resistance, and blood pressure at that stage can be fully normalized by autonomic blockade. As hypertension advances, a hyperkinetic circulation is less evident, since beta-adrenergic responsiveness and cardiac compliance tend to decrease. Simultaneously hypertrophy of the resistance vessels increases the baseline vascular resistance and the vessels' responsiveness to constrictive stimuli. Eventually a picture of a normal cardiac output/high vascular resistance typical for established essential hypertension emerges. As the blood vessels become hyperreactive, the same degree of vasoconstriction/blood pressure elevation can be achieved with less sympathetic tone. In that phase the sympathetic overactivity is less evident, as the brain resets itself to maintain the same blood pressure elevation with a small amount of sympathetic discharge. While sympathetic overactivity may be less evident in established hypertension, it remains an important pathophysiologic factor, not only for the maintenance of blood pressure, but also for a number of other abnormalities in hypertension. Hypertension is intimately associated with higher levels of pressure-unrelated risk for development of atherosclerosis: dyslipidemia, overweight, and hyperinsulinemia. Furthermore, a number of factors in hypertension favor a poorer outcome from coronary heart disease. These pressure-independent factors increase the risk of coronary thrombosis, arrhythmic deaths, and coronary spasms. Sympathetic overreactivity appears to be crucially implicated in the evolution of this added coronary risk in hypertension. Understanding the pathophysiology of coronary risk and its relationship to sympathetic overreactivity in hypertension is helpful in seeking further improvements in clinical practice. At present antihypertensive treatment is less efficacious in reducing coronary events in hypertension than would be expected. Judicious use of appropriate drugs promises to further improve the efficacy of antihypertensive treatment in those patients who, in addition to high blood pressure, also have other associated risk factors.

Cardiovasc Drugs Ther 1994;8:11-20

Key words. hemodynamics, sympathetic tone, metabolic syndrome, insulin resistance

In the beginning of this century, as soon as clinical blood pressure measurement became available, inves- tigators started to focus on the possible role of sympathetic overactivity as a mechanism for elevated blood pressure. In 1905, Geisbock [1] described among his patients with polycythemic hypertension an "unusual frequency of directors of big enterprises who had demanding jobs and who, due to psychic overwork, became nervous." In 1933, in one of the earlier reports on hypertension in the United States, Ayman [2] described the passive-submissive personality of his patients. However in the 1960s and 1970s, the interest in the role of the nervous system in hypertension substantially declined. A few factors contributed to this state of affairs. First was that arterial baroreceptors are reset to maintain higher blood pressure after the development of experimental hypertension [3] and that removal of baroreceptor inhibition does not result in permanent hypertension $[4,5]$. The second important factor in the non-neurogenic orientation of the hypertension research reflects animal modeling of hypertension. Research is the art of the feasible, and phenomena that are hard to measure or difficult to model receive less attention. The ease of generating hypertension in animals with stenosis of the renal artery, partial ablation of the kidney, DOCA/salt, and other interventions influenced the direction of research. In contrast, it still is very difficult to generate experimentally a neurogenic hypertension. Baroreceptor debuffering failed mainly because the baroreceptors seem to regulate blood pressure variability but not the setting of the average blood pressure level. Repeated stressors such as noise [6], electrical stimulation of the paleocortex [7], or shock/avoidance in dogs [8] failed to induce long-lasting and selfperpetuating hypertension.

The third reason for doubts about the role of the nervous system in hypertension stems from human research: Plasma catecholamines are elevated in young subjects with mild hypertension but not in more advanced forms of hypertension $[9,10]$.

The failure to create an animal model of neurogenic hypertension is somewhat fortuitous, as it forced in-

Address for correspondence: Stevo Julius, M.D., Sc.D., University of Michigan Medical School, Division of Hypertension, 3918 Taubman Center, Ann Arbor, MI 48109-0356, USA. 
vestigators to concentrate on human investigations. I strongly believe that animal modelling, while explaining how various organs suffer in response to high blood pressure, has little to offer for understanding the etiology of human hypertension. How do the inbred animal models resemble human hypertension and which model applies to which subset of patients with hypertension? Since animal experimentation up to today have failed to elucidate the nature of human hypertension, and the methods of clinical investigation grew more sophisticated, the pendulum has switched towards an increasing interest in the role of the nervous system in human hypertension. Furthermore, awareness is increasing that the nervous system is intimately involved in the pathophysiology of diverse forms of experimental hypertension. Destruction of the AV3V region in the midbrain prevents the occurrence of renovascular, DOCA, and other sodiumsensitive forms of hypertension [11]. Studies of the Okamoto spontaneously hypertensive rat, a strain claimed to be "most similar to human hypertension," also shows a strong neurogenic component in its pathophysiology $[12,13]$.

In this review I will show that the role of autonomic abnormality in human hypertension is well understood; that we now can explicate the transition from early phases of hypertension, which clearly is neurogenic, to later phases, which appear to be less neurogenic; and that understanding the pathophysiologic role of the nervous system may explain many clinically important aspects of hypertension.

\section{The Changing Face of Autonomic Abnormality in Hypertension}

Young patients with borderline hypertension frequently show a hyperkinetic state of increased cardiac output and a faster heart rate [14-20]. The increase of heart rate and cardiac output in these individuals is neurogenic and can be abolished with receptorblocking agents [21]. Interestingly, the hyperkinetic state is due both to more beta-adrenergic drive and less parasympathetic inhibition of the heart. This, in turn, suggests that abnormality is of central nervous origin and emanates from the medulla oblongata, where sympathetic and parasympathetic tone are integrated in a reciprocal fashion. Plasma norepinephrine levels in hyperkinetic borderline hypertension are elevated [22]. Blood pressure elevation, per se, is also neurogenic; a complete autonomic blockade, including alpha-adrenoreceptor blockade, normalizes the blood pressure in these patients [23]. Recently direct microneurography documented a consistent elevation of the number of sympathetic impulses in the peroneal nerve of patients with borderline hypertension [24].

These lines of evidence strongly support the im- portance of the autonomic nervous abnormalities in borderline hypertension. Nevertheless, these observations leave a number of open questions. First is whether patients studied in laboratories are representative of the average population of patients with hypertension. For example, it is possible that healthconscious, concerned, and a priori anxious patients are over-represented among volunteers for studies in highly specialized, hospital-based laboratories. Pathophysiologic abnormalities in them may be an acute reaction to the procedure of measurement unrelated to the mechanism of hypertension. However, this is not the case. In the field study in Tecumseh we utilized noninvasive and nonthreatening methods to assess hemodynamics in unselected subjects, many of whom were unaware of having a blood pressure "problem." Nevertheless the findings were similar as in the hospital laboratory; in excess of $30 \%$ of all subjects with borderline hypertension had a hyperkinetic circulation, their plasma norepinephrine levels were elevated, they came from families with higher blood pressure, and these individuals, who during the recent exam on average were 32 years of age, showed significant blood pressure elevation already as children at 7 years of age [22]. These findings suggest that a neurogenic borderline hypertensive is frequently seen in the general population and that the condition starts very early in life.

A second set of questions pertains to the natural history of neurogenic borderline hypertension. Do patients with hyperkinetic borderline hypertension later develop sustained hypertension? If the answer is yes, why do we find elevated resistance and a normal cardiac output in established hypertension? If they start with a high cardiac output and end up with elevated vascular resistance, what is the mechanism of this hemodynamic transition?

The first of these questions can be answered with relative ease. A number of epidemiologic studies document tachycardia, the hallmark of the hyperkinetic state, to be predictive of future hypertension [25-27]. Furthermore, as the blood pressure increases from borderline to established higher values, cohort studies have documented the transition from a high output to a high resistance state. Initial short studies (up to 5 years), while confirming the hemodynamic transition, were unable to convincingly show the development of established hypertension in these patients. More recently, Dr. Lund Johansen reported on 20 years of follow-up in his subjects with hyperkinetic borderline hypertension [28]. In this unique study, after 20 years almost all subjects developed a treatment-requiring, high-resistance type of hypertension.

We believe that the transition from the high cardiac output to a high resistance reflects a decrease of cardiac and an increase of vascular responsiveness in the course of hypertension. Two elements affect the decreased cardiac responsiveness: prolonged sym- 
pathetic stimulation leads to a decrease of betaadrenergic responsiveness and the elevated blood pressure causes an early decrease of cardiac compliance, which, in turn, decreases stroke volume [29]. Simultaneously with this decrease of heart rate and stroke volume, the longstanding blood pressure elevation tends to accentuate the vasoconstriction in resistance vessels. Many years ago Dr. Bjorn Folkow first proposed the principle and later experimentally demonstrated that the geometry of a vessel's wall affects the resistance responsiveness of that vessel [30]. Blood pressure elevation leads to vascular hypertrophy and a thickening of the medial (muscular) layer in the vessel's wall. As the blood vessel constricts, the thicker wall encroaches more on the lumen. Vascular resistance is a fourth power function of the radius and vasoconstriction in patients with hypertrophic blood vessels causes a larger increase of vascular resistance than in normal subjects. This enhancement of vasoconstriction is nonspecific and the blood vessels are hyper-responsive to all vasoconstrictive stimuli. Such early changes in vascular structure have been documented in hypertension [31,32]. There is some discussion as to whether, in addition to these nonspecific changes hypertensive patients also show specific alpha-adrenergic hyper-responsiveness [33-35].

All these changes contribute to an alteration of the hypertensive phenotype. The telltale signs of neurogenic involvement in early hypertension - the fast heart rate and increased cardiac output - are not evident in established hypertension. What looked as clearly neurogenic disease in the beginning later appears unrelated to sympathetic overactivity. However, in addition to these changes in the peripheral responsiveness in the course of hypertension, the actual sympathetic tonic discharge from the central nervous system appears also to decrease slowly. Plasma norepinephrine values are elevated in young patients with hyperkinetic hypertension [22] but such an elevation cannot be documented in older subjects with established hypertension $[9,10]$. As hypertension advances, a similar downward trend in sympathetic activity has also been observed in studies utilizing norepinephrine "spillover" rates to assess the sympathetic tone [36]. What could be the mechanism of this resetting of sympathetic tone? In the absence of a direct answer, we recently proposed a hypothesis that provides the conceptual framework to explain this transition [37].

The hypothesis is based on numerous observations about the "blood pressure seeking property of the central nervous system." In order to tightly regulate circulation, the autonomic control of circulation functions as a negative feedback system (Figure 1). Whenever there is a perturbance in circulation, the feedback trends to determine the magnitude of the response in order to assure a new equilibrium. As Figure 1 illustrates, in circulation the feedback from the pe-

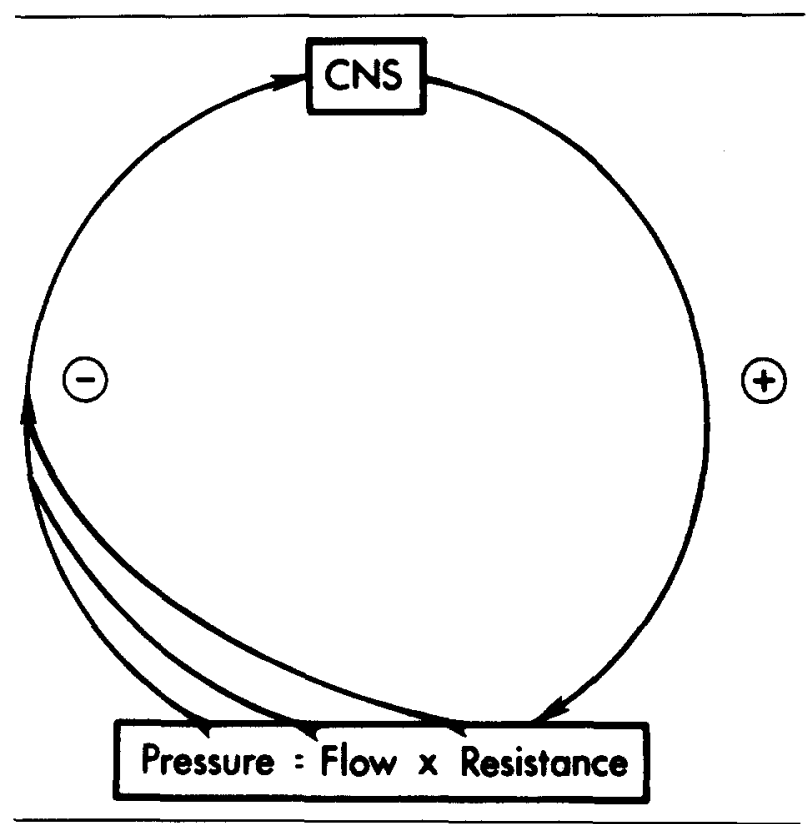

Fig. 1. The general scheme of the negative feedback from the circulation to the central nervous system (CNS). Adapted from data in Julius et al. [37] with permission.

riphery to the brain must be related to one of the primary circulatory variables: pressure, flow, or resistance. In terms of feedback loops, the variable that is most tightly controlled is the regulated variable. Dr. Guyton correctly points out that the long-term purpose of circulation must be to regulate the flow [38]. In his volume-dependent models, when the minute volume (cardiac output) is perturbed, pressure and resistance adjusts to secure an optimal flow (autoregulation). Under those circumstances the flow is the regulated variable.

However, we maintain the central nervous system subserves the circulation by regulating blood pressure. It will be shown that under a number of circumstances the central nervous system permits wide variations of resistance and flow but very closely regulates the pressor response. To follow this argument the reader should become familiar with the graphic presentation of the basic relationship between flow, pressure, and resistance given in Figure 2. The degree to which the flow increases in response to an elevation of the pressure depends on resistance to flow. Resistance, in turn, is largely dependent on the crosssectional area of all vascular lumina in the circulation. When the blood vessels are widely open (Figure 2 , isoresistance, line 1) resistance is low and a small increase of pressure elicits a large increase of flow. When the blood vessels are constricted and resistance is high, a large increase of pressure results in only a small increase of flow (Figure 2, isoresistance, line 5). This diagram permits simultaneous assessment of the relationship between the three principal components 


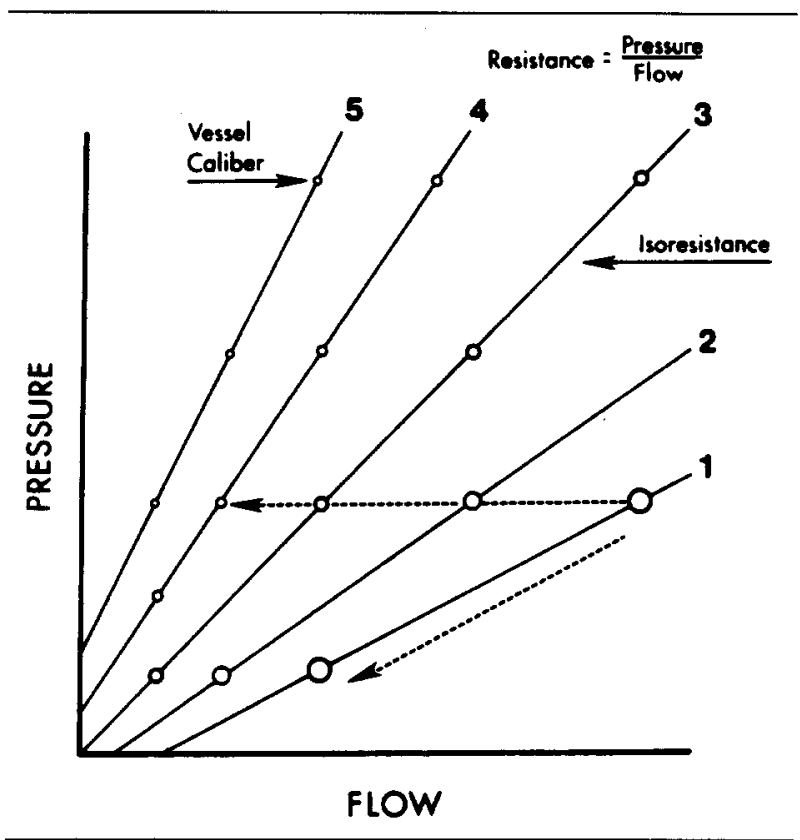

Fig. 2. The pressure-flow-resistance relationship. The diagonal lines are lines of isoresistance. The lowest diagonal lines represent low resistance, and the highest lines represent high resistance. Note that the vascular caliber at low resistance is larger and that small increases in pressure cause a large increase in flow. At the high resistance line the vascular caliber is narrow and a large increase in pressure causes only a small increase in flow. The horizontal vector represents a decrease in flow, associated with an increase in resistance and no change in pressure. The diagonal, downwardly pointing vector represents a decrease in flow with an unchanged resistance and a fall in blood pressure. Adapted from data in Julius et al. [s7].

of circulation. Pressure and flow can be read from the corresponding axis, whereas the direction of the arrow in relationsip to the isoresistance lines denotes a change in resistance.

Examples of how the central nervous system preserves the blood pressure response are shown in Figures 3 and 4 . The point of both illustrations is that under proper experimental circumstances one can prevent the usual hemodynamic response but this will not affect the magnitude of the blood pressure response. For example, in Figure 3 the usual response to isometric exercise, which is a rise in cardiac output, did not occur in patients with poor myocardial function, but blood pressure response was preserved. Instead of an increase of cardiac output, the poor cardiac function group responded with an increase of vascular resistance [39]. An example in the opposite direction is given in Figure 4. The usual hemodynamic response to hindquarter compression in dogs is resistancemediated neurogenic increase of blood pressure [40]. When the increase of resistance is prevented with alpha-adrenergic blockade, the blood pressure response is preserved through an increase of cardiac

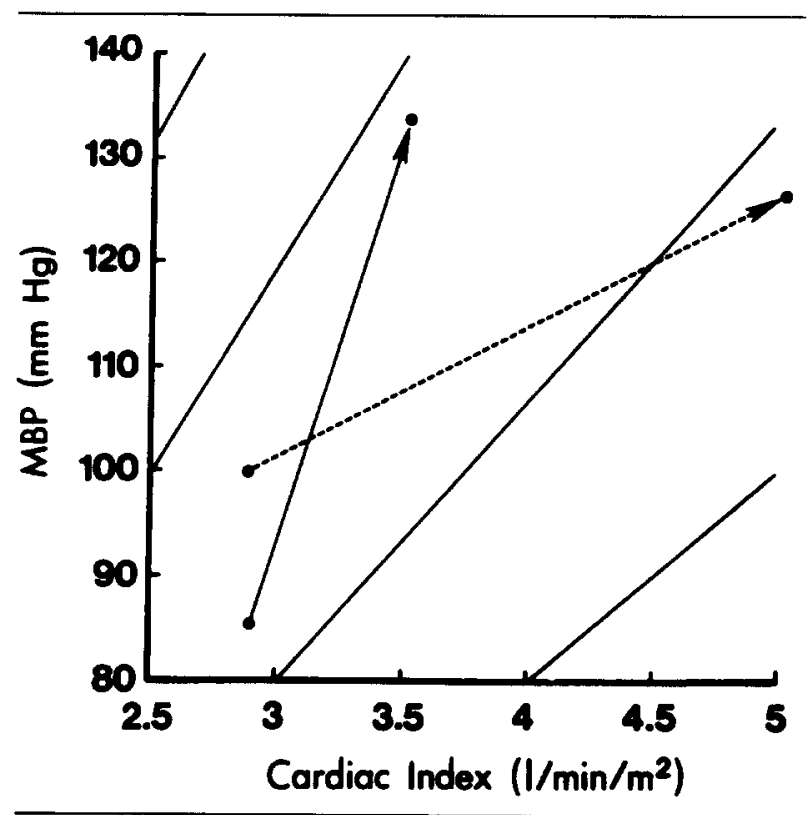

Fig. 3. Response to isometric exercise in patients recovering from myocardial infarction. Six subjects had a normal cardiac output response $(\cdots \rightarrow \rightarrow)$. Eight patients had poor cardiac function and failed to increase output $(\longrightarrow) . M B P=$ mean blood pressure. Adapted from data in Bacelli et al. [39].

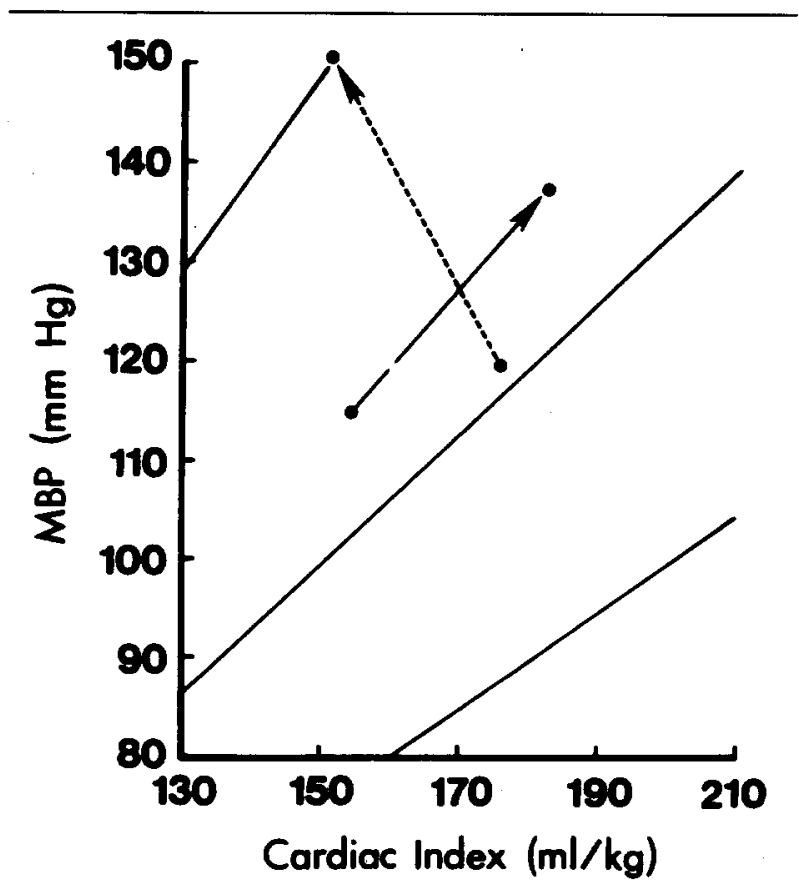

Fig 4. Response to 60 minutes of hindquarter compression in eight chloralose-anesthetized dogs. $\rightarrow-\cdots \rightarrow$, , response before phenoxybenzamine; $\longrightarrow$ response to 60 minutes of compression after $1 \mathrm{mg} / \mathrm{kg}$ phenoxybenzamine (i.v.). $M B P=\operatorname{mean}$ blood pressure. Adapted from data in Julius et al. [41]. 
output [41]. This principle that blood pressure response is obligatory and stereotypical but the underlying hemodynamics can be either cardiac or vascular, depending on which system is rendered unresponsive, has also been documented for mental arithmetic [42], isometric exercise [43], stellate ganglion stimulation [44], and response to noise [45].

Preservation of blood pressure response in the experiments cited above implies that feedback information to the central nervous system is pressure related and independent of the state of the resistance or flow. To be able to stabilize response at the desired blood pressure level, the brain must be capable of sensing the achieved blood pressure. It follows that the direction (to vessels or the heart) and the magnitude of the central nervous discharge largely depends on responsiveness of the peripheral organs. Within the context of this blood pressure seeking property of the central nervous system, the observed sequence of events in borderline and advanced hypertension is to be expected. If the brain in hypertension seeks to maintain a higher average blood pressure level as vascular responsiveness increases with the progression of hypertension, the brain can achieve the same blood pressure level with less sympathetic firing. The primary mechanism of hypertension may still be neurogenic, but due to increased vascular responsiveness the absolute sympathetic tone will not be increased.

In summary, there is good evidence for a strong neurogenic component in early phases of hypertension, particularly in so-called hyperkinetic borderline hypertension (high cardiac output and a fast heart rate). This condition may be present in about $30 \%$ of patients with borderline hypertension, and it has been shown that these patients eventually do develop established treatment-requiring hypertension. As hypertension escalates the hemodynamic pattern changes from a high cardiac output to a high resistance pattern. The transition from high cardiac output to high resistance is best explained by alteration in the structure and responsiveness of the heart and blood vessels. Decreased cardiac compliance and diminished beta-adrenergic responsiveness tend to decrease cardiac output, whereas the development of vascular hypertrophy increases vascular resistance. In parallel the sympathetic tone appears to be down-regulated, since with emerging vascular hyperresponsiveness less sympathetic drive is needed to maintain the vasoconstriction-related hypertension.

\section{Sympathetic Overactivity and Multiple Coronary Risk in Hypertension}

Blood pressure elevation is only part of a larger problem in patients with borderline hypertension. Behind the facade of mild blood pressure elevation hides a number of other pathophysiologic abnormalities. Of particular interest is the coaggregation of coronary risk factors with blood pressure elevation in borderline and established hypertension. These can be broken down into proatherogenic factors and factors that increase the risk of complications in patients who have already developed coronary heart disease. We will show that the autonomic nervous system plays an important role in the development of these risk factors.

\section{Acceleration of atherosclerosis}

Table 1 shows atherosclerotic risk factors in patients with borderline hypertension in Tecumseh. It should be pointed out that blood pressure elevation in these patients is minimal; their clinical reading was 130/94 $\mathrm{mmHg}$, but when they measured their own blood pressure at home the average reading was $126 / 80$ mmHg [46]. Furthermore, when patients with "white coat hypertension" (normal blood pressure at home) were compared to the "sustained" hypertension subgroup (high blood pressure both in the clinic and at home), subjects with only transient hypertension had significantly higher levels of coronary risk than the normotensive population [47].

The coaggregation of coronary risk with hypertension is astonishing. From the very beginning of the disease in its mildest possible form, patients are not only burdened with a higher blood pressure level but are also overweight, their HDL cholesterol is decreased, and their cholesterol, triglyceride, and insulin levels are elevated. All of these are known risk factors for coronary heart disease. Obviously the higher coronary risk in hypertension does not reflect only the blood pressure elevation but also these other associated risk factors. Why should all these abnormalities be found in the same persons? I will marshal evidence to suggest that the increased sympathetic tone, which maintains the higher blood pressure, is also responsible for the elevation of plasma insulin levels in borderline hypertension. Through its "trophic" effect on smooth muscle cell growth [48-50], high insulin is an independent risk factor for atherosclerosis [51-53]. Furthermore, high insulin levels in insulinresistant states may contribute to dyslipidemias [54].

High insulin is a sign of insulin resistance in hypertension, and the skeletal muscles are the major site of the tissue resistance to insulin [55,56]. Enhanced sympathetic drive may be conducive to insulin resistance through a number of mechanisms. First, it is known that beta-adrenergic stimulation causes a receptor-mediated insulin resistance [57]. Second, chronic beta-adrenergic stimulation causes an increase in the number of fast-twitch insulin resistant fibers [58].

Alpha-adrenergic vasoconstriction is the third mechanism by which sympathetic overactivity could lead to insulin resistance. We first proposed the concept [59] and later provided experimental evidence [60] for the notion that vasoconstriction may decrease the glucose delivery to the skeletal muscle and 
Table 1. Indices of body size and risk factors in the two groups ${ }^{\mathrm{a}}$

\begin{tabular}{lccc}
\hline & & Borderline \\
Index & $\begin{array}{l}\text { Normotensive subjects } \\
\text { (sample size) }\end{array}$ & (sample size) & $\mathrm{p}^{\mathrm{b}}$ \\
\hline Weight, kg & $74.3 \pm 0.5(801)$ & $87.7 \pm 1.3(123)$ & $<.0001$ \\
Height, cm & $170.2 \pm 0.2(801)$ & $170.0 \pm 0.6(123)$ & $\mathrm{NS}$ \\
Overweight, \% & $13.6 \pm 0.7(799)$ & $30.1 \pm 1.9(123)$ & $<.0001$ \\
Triceps skin folds, mm & $18.3 \pm 0.3(756)$ & $20.8 \pm 0.8(112)$ & $<.005$ \\
Biceps skin folds, mm & $10.4 \pm 0.2(756)$ & $12.6 \pm 0.6(112)$ & $<.001$ \\
Subscapular skin folds, mm & $20.6 \pm 0.4(756)$ & $24.1 \pm 0.9(112)$ & $<.0005$ \\
Suprascapular skin folds, mm & $23.0 \pm 0.4(754)$ & $27.6 \pm 1.1(112)$ & $<.0001$ \\
Cholesterol, mM/l & $4.54 \pm 0.03(684)$ & $1.04 \pm 0.03(102)$ & $<.0001$ \\
High-density lipoprotein, mM/l & $1.12 \pm 0.01(684)$ & $1.52 \pm 0.08(86)$ & $126 \pm 11(81)$ \\
Triglycerides, mM/l & $1.07 \pm 0.03(598)$ & $5.3 \pm 0.06(80)$ & $<.001$ \\
Insulin, pM/l & $88 \pm 3(581)$ & $0.200 \pm 0.011(67)$ & $<.0001$ \\
Glucose, mM/L & $5.1 \pm 0.02(563)$ & $0.86 \pm 0.01(25)$ & $<.001$ \\
Insulin/glucose ratio & $0.155 \pm 0.004(485)$ & & $<.005$ \\
Waist/hip ratio & $0.83 \pm 0.01(156)$ & & \\
\hline
\end{tabular}

${ }^{\mathrm{a}}$ Values are mean \pm SEM.

${ }^{b}$ Analysis of covariance. NS indicates not significant.

Adapted from data in Julius et al. [46].

thereby cause a relative resistance to the effects of insulin. Figure 5 shows the effect of reflex vasoconstriction of glucose utilization in the human forearm [60]. In this experiment we infused insulin into the brachial artery and measured the insulin-induced glucose utilization in the forearm. Reflex vasoconstriction in the forearm was induced by inflating blood pressure cuffs on subjects' thighs, thereby decreasing the right atrial pressure, which, in turn, triggers increased sympathetic tone via cardiopulmonary mechanoreceptors. As the figure shows, reflex vasoconstriction caused a decrease of insulin-stimulated glucose uptake in the forearm.

Our experiments are acute and the question arises as to whether the results are applicable to chronic hypertension. We think that chronic sympathetic overstimulation and longstanding blood pressure elevation in hypertension lead to vascular rarefaction, which then may become the mechanism for chronic insulin resistance in hypertension. A decrease of capillary density in various organs, including the skeletal muscles, in hypertension has been documented [6164].

\section{Enhanced risk of coronary morbidity}

Coronary thrombosis. Two factors may favor coronary thrombosis in hypertension and both of them likely reflect increased sympathetic tone. First is high hematocrit, which is often found in hypertension [65]. A high hematocrit is an independent predictor of coronary mortality, most likely through an increase of blood viscosity, which increases the chances of coronary thrombosis $[66,67]$. Patients with hypertension have significantly decreased plasma volume [68], and the higher hematocrit values reflect this contraction of the intravascular volume. Infusion of norepinephrine causes an acute decrease of plasma volume [69], and beta-adrenergic blockade with propranolol causes a similar decrease of plasma volume [70]. The most likely mechanism for the fall in plasma volume after these pharmacologic interventions is an alphaadrenergically mediated increase in postcapillary venous resistance, leading to an increase in the capillary pressure. It stands to reason that sympathetic vasoconstriction may contribute to decreased plasma volume and an increase of hematocrit in hypertension.

The second mechanism conducive to coronary thrombosis in hypertension is increased platelet activity. Plasma thromboglobulin, a measure of platelet turnover, is elevated in hypertension and the elevation correlates to increased plasma adrenaline levels in these patients [71].

Tendency to sudden death. Left ventricular hypertrophy is a major risk factor for arrhythmias and sudden death [72]. At this point the reader should be reminded of the evidence presented earlier in this paper, of an increased sympathetic and decreased parasympathetic cardiac tone in hypertension. Initially, as hypertension advances, cardiac sympathetic tone appears to decrease, but later when cardiac performance decreases, the heart again becomes more dependent on enhanced sympathetic drive. The decreased parasympathetic tone is a constant feature both in borderline [21] and the later established phase of hypertension [73]. There is good experimental evidence that increased sympathetic tone and decreased parasympathetic activity are arrhythmogenic [74,75]. It there- 


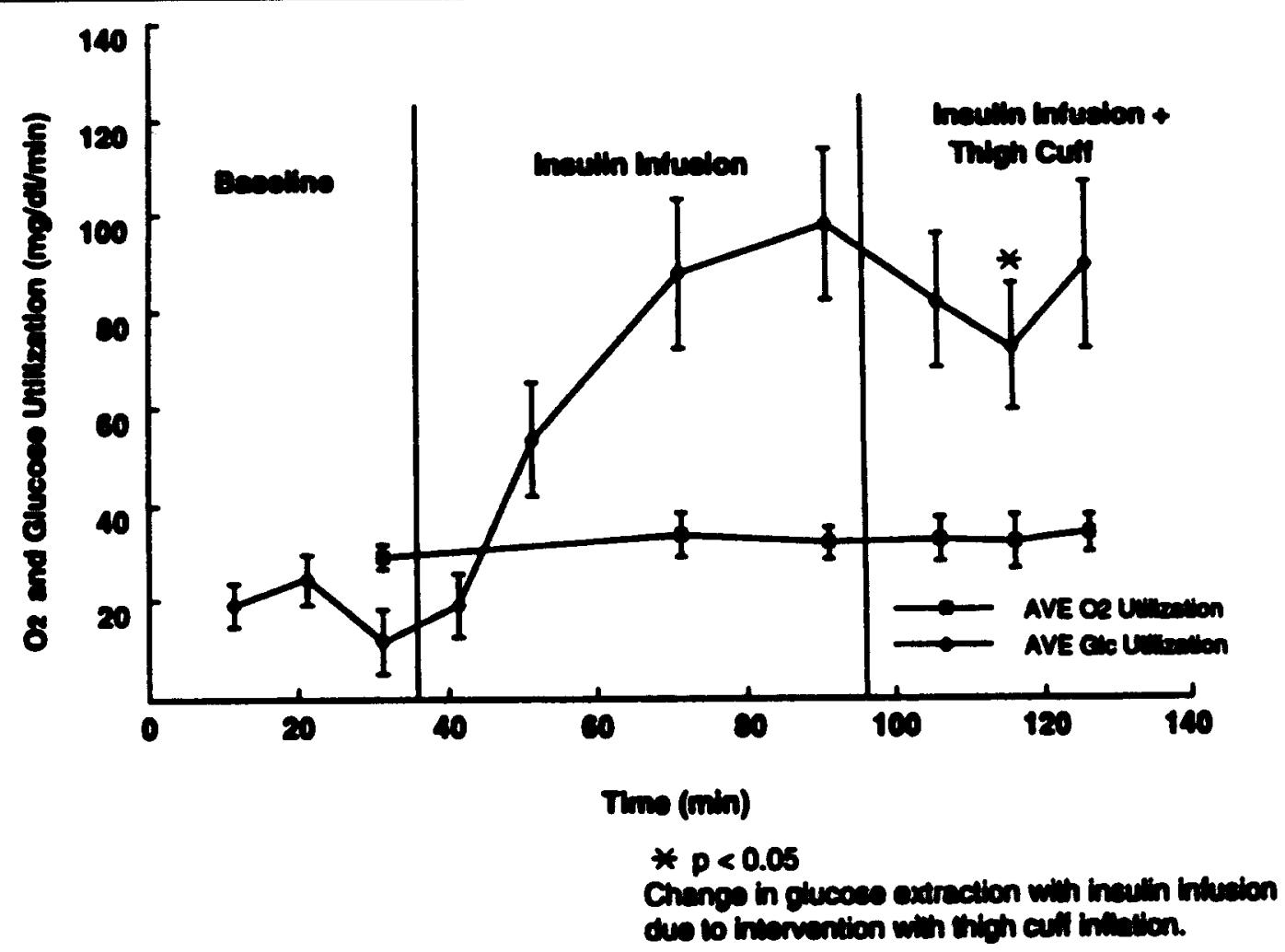

Fig. 5. Line graph shows effect of insulin infusion and reflex sympathetic activation on glucose and oxygen utilization in the forearm of 14 healthy volunteers. Reflex activation was elicited by inflation of blood pressure cuffs placed around subjects' thighs. Inflation of the cuff to $40 \mathrm{mmHg}$ decreases the venous return and thereby decreases the stretch of cardiopulmonary receptor, which, in turn, elicits sympathetic vasoconstriction in the forearm. ${ }^{*}$ Change from insulin to insulin plus thigh cuff, $p<0.03 . A V E=a v$ erage; Glc = glucose. Adapted from data in Jamerson et al. [60].

fore stands to reason that increased sympathetic and decreased parasympathetic tone in hypertension are conducive to arrhythmias.

Increased ventricular size by itself favors arrhythmias. Again, sympathetic activity may independently contribute to this additional risk factor for arrhythmias. Sympathetic stimulation is recognized as a "trophic" factor. In tissue cultures norepinephrine stimulates the growth and hypertrophy of cardiac cells [76]. Furthermore, sympathetic stimulation of kidneys increases the release of renin, leading to high plasma angiotensin values, and in mild hypertension high renin is characteristically found in patients with elevated plasma norepinephrine values [23]. Angiotensin is also a known trophic factor [77]. Thus both angiotensin and norepinephrine, when elevated, will further aggravate the pressure-induced tendency for cardiac hypertrophy.

\section{Coronary spasms}

A final mechanism by which sympathetic overactivity may contribute to coronary pathology in hypertension is through its trophic effect on vascular smooth muscle hypertrophy. Hypertrophy of the smooth muscle in the medial layer of a vessel's wall causes the wall to encroach upon the lumen and this potentiates vasoconstriction. There is good evidence that coronary resistance vessels in hypertension are hyper-responsive to vasoconstriction stimuli [78]. It is also reasonable to assume that sympathetic stimulation may play a role in this hyper-reactivity. In a case of another vascular bed - the human forearm - , our own data support the role of sympathetic overactivity in the genesis of vascular hypertrophy in mild hypertension. Residual vascular resistance during maximal vasodilatation, a measure of the thickness of the wall at the point when the smooth muscles are fully relaxed, is elevated in borderline hypertension, and in these subjects there was a positive correlation between minimal forearm resistance and plasma norepinephrine values [79]. Such an effect of sympathetics is most likely to be evidenced also in the coronary vasculature.

\section{Clinical Implication}

One of the major puzzles in clinical hypertension is the lesser efficacy of antihypertensive agents in re- 
gards to coronary protection and prevention $[80,81]$. For example, both strokes and coronary heart disease show a linear relationship to increasing blood pressure levels, but blood pressure reduction is much more effective in decreasing strokes than in reducing coronary events in hypertension. Whereas this finding seems to be paradoxical to some epidemiologists and they have difficulties in accepting it, to a student of the pathophysiology of hypertension this state of affairs is fully expected. The syndrome of hypertension is complex and, in addition to blood pressure elevation, also includes a number of metabolic and hemodynamic abnormalities, which are, in their own right, conducive to coronary morbidity. Understanding the pathophysiology of these associated factors is the precondition for a more rational and potentially more efficacious treatment of hypertension. Since autonomic abnormality plays a major role in the genesis of these associated risk factors, it stands to reason that centrally acting antihypertensive agents ought to be particularly useful in that regard. Future research is needed to evaluate whether this theoretical expectation can be translated into a demonstrable clinical advantage.

\section{References}

1. Geisbock W. Die bedeutung der blutdruckmessung fur die praxis. Dtsch Arch Klin Med 1905;83:363-374.

2. Ayman D. Personality type of patients with arteriolar essential hypertension. Am J Med Sci 1933;186:213-223.

3. McCubbin JW, Green JH, Page IH. Baroreceptor function in chronic renal hypertension. Circ Res 1956;4:205-210.

4. Cowley AW Jr, Liard JF, Guyton AC. Role of the baroreceptor reflex in daily control of arterial blood pressure and other variables in dogs. Circ Res 1973;32:564-576.

5. Nathan MA, Reis DJ. Chronic labile hypertension produced by lesions of the nucleus tractus solitarii in the cat. Circ Res 1977;40:72-81.

6. Rothlin E, Cerletti A, Emmenegger H. Experimental psycho-neurogenic hypertension and its treatment with hydrogenated ergot alkalosis (hydergine). Acta Med Scand 1956; 154(Suppl 312):27-35.

7. Folkow B, Rubinstein EH. Cardiovascular effects of acute and chronic stimulation of the hypothalamic defense area in the rat. Acta Physiol Scand 1966;68:48-57.

8. Anderson D, Kearns W. Better W. Progressive hypertension in dogs by avoidance conditioning and saline infusion. Hypertension 1983;5:286-291.

9. Goldstein DS. Plasma norepinephrine in essential hypertension. A study of the studies. Hypertension 1981;3:48-52.

10. Goldstein DS. Plasma catecholamines and essential hypertension. An analytical review. Hypertension 1983;5:86-99.

11. Brody MJ, Johnson AK. Role of the anteroventral third ventricle region in fluid and electrolyte balance, arterial pressure regulation, and hypertension. In: Martini L, Ganong WF, eds. Frontiers in Neuroendocrinology, Vol. 6. New York: Raven Press, 1989:249-292.

12. Lundin S, Nordlander M. Hemodynamics in the spontaneously hypertensive rat. In Zanchetti A, Tarazi RC, eds. Handbook of Hypertension, Vol. 7: Pathophysiology of Hy- pertension - Cardiovascular Aspects. Amsterdam: Elsevier Science, 1986:179-198.

13. Lundin $\mathrm{S}$, Ricksten $\mathrm{S}-\mathrm{E}$, Thoren $P$. Renal sympathetic activity in the spontaneous hypertensive rats and normotensive controls, as studied by three different methods. Acta Physiol Scand 1984;120:265.

14. Julius S, Conway J. Hemodynamic studies in patients with borderline blood pressure elevation. Circulation 1968;38: 282-288.

15. Widimsky J, Fejfarova MH, Fejfar Z. Changes of cardiac output in hypertensive disease. Cardiologia 1957;31:381389.

16. Eich RH, Peters RJ, Cuddy RP, Smulyan H, Lyons RH. The hemodynamics in labile hypertension. Am Heart $J$ 1962; 63:188-195.

17. Lund-Johansen P. Hemodynamic alterations in early essential hypertension: Recent advances. In: Gross F, Strasser T, eds. Mild Hypertension: Recent Advances. New York: Raven Press, 1983:237-249.

18. Frohlich ED, Kozul VJ, Tarazi RC, Dustan HP. Physiological comparison of labile and essential hypertension. Circ Res 1970;26(Suppl I):55-69.

19. Messerli FH, De Carvalho JGR, Christie B, Frohlich ED. Systemic and regional hemodynamics in low, normal and high cardiac output borderline hypertension. Circulation 1978;58:441-448.

20. Messerli FH, Frohlich ED, Suarez DH, Reisin E, Dreslinski GR, Dunn FG, Cole FE. Borderline hypertension: Relationship between age, hemodynamics and circulating catecholamines. Circulation 1981;64:760-764.

21. Julius S, Pascual AV, London R. Role of parasympathetic inhibition in the hyperkinetic type of borderline hypertension. Circulation 1971;44:413-418.

22. Julius S, Krause L, Schork N, et al. Hyperkinetic borderline hypertension in Tecumseh, Michigan. J Hypertens 1991;9; $77-84$.

23. Esler M, Julius S, Zweifler A, et al. Mild high-renin essential hypertension: Neurogenic human hypertension? N Engl $J$ Med 1977;296:405-411.

24. Anderson EA, Sinkey CA, Lawton WJ, Mark AL. Elevated sympathetic nerve activity in borderline hypertensive humans: Evidence from direct intraneural recordings. Hypertension 1989;14:177-183.

25. Levy RL, Hillman CC, Stroud WD, White PD. Transient hypertension: Its significance in terms of later development of sustained hypertension and cardiovascular-renal diseases. JAMA 1944;126:829-833.

26. Paffenbarger RS Jr, Thorne MC, Wing AL. Chronic disease in former college students - VIII. Characteristics in youth predisposing to hypertension in later years. Am J Epidemiol 1968;88:25-32.

27. Stamler J, Berkson DM, Dyer A, et al. Relationship of multiple variables to blood pressure - Findings from four Chicago epidemiologic studies. In Paul O, ed. Epidemiology and Control of Hypertension. Miami, FL: Symposia Specialists, 1975:307-352.

28. Lund-Johansen $P$, Omvik P. Hemodynamic patterns of untreated hypertensive disease. In: Laragh JH, Brenner BM, eds. Hypertension: Pathophysiology, Diagnosis, and Management. New York: Raven Press, 1990:305-327.

29. Julius S, Randall OS, Esler MD, Kashima T, Ellis CN, Bennett J. Altered cardiac responsiveness and regulation in the normal cardiac output type of borderline hypertension. Circ Res 1975;36-37(Suppl I):I199-I207. 
30. Folkow B. Physiological aspects of primary hypertension. Physiol Rev 1982;62:347-503.

31. Conway J. A vascular abnormality in hypertension. A study of blood flow in the forearm. Circulation 1963;27:520-529.

32. Sivertsson R, Sannerstedt R, Lundgren Y. Evidence for peripheral vascular involvement in mild elevation of blood pressure in man. Clin Sci Mol Med 1976;51:65s-68s.

33. Weidmann P, Grim M, Meier A, et al. Pathogenic and therapeutic significance of cardiovascular pressor reactivity as related to plasma catecholamines in borderline and established essential hypertension. Clin Exp Hypertens 1980;2: 427-449.

34. Amann FW, Bolli P, Kiowski W, Buhler FR. Enhanced alpha-adrenoreceptor-mediated vasoconstriction in essential hypertension. Hypertension 1981;3(Suppl I):I119-I123.

35. Philipp TH, Distler A, Cordes U. Sympathetic nervous system and blood-pressure control in essential hypertension. Lancet 1978;2:959-963.

36. Esler M, Jackman G, Bobik A, et al. Norepinephrine kinetics in essential hypertension. Defective neuronal uptake of norepinephrine in some patients. Hypertension 1981;3: 149-156.

37. Julius S. Editorial review: The blood pressure seeking properties of the central nervous system. $J$ Hypertens 1988;6: $177-185$.

38. Guyton AC, Coleman TG. Quantitative analysis of the pathophysiology of hypertension. Circ Res 1969;24-25 (Suppl I):1-19.

39. Baccelli G, Valentini R, Gregorini L, et al. Haemodynamic effects of isometric handgrip exercise in patients convalescent from myocardial infarction. Clin Exp Pharmacol Physiol 1978;5:607-615.

40. Julius S. Sanchez R, Malayan S, et al. Sustained blood pressure elevation to lower body compression in pigs and dogs. Hypertension 1982;4:782-788.

41. Julius S, Brandt D. Hemodynamic plasticity during hindquarter compression. Acta Physiol Scand 1988;133(Suppl 571):107-116.

42. Ulrych $M$. Changes of general haemodynamies during stressful mental arithmetic and nonstressing quiet conversation and modification of the latter by beta-adrenergic blockade. Clin Sci 1969;36:453-461.

43. MacDonald HR, Sapru RP, Taylor SH, Donald KW. Effect of intravenous propranolol on the systemic circulatory response to sustained handgrip. Am J Cardiol 1966;18:333343.

44. Liard JF, Tarazi RC, Ferrario CM, Manger WM. Hemodynamic and humoral characteristics of hypertension induced by prolonged stellate ganglion stimulation in conscious dogs. Circ Res 1975;36:455-465.

45. Andren L, Hansson L. Eggertsen R, Hedner T, Karlbert BE. Circulatory effects of noise. Acta Med Scand 1983;213: 31-35.

46. Julius S, Jamerson K, Mejia A, Krause L, Schork N, Jones $\mathrm{K}$. The association of borderline hypertension with target organ changes and higher coronary risk. Tecumseh Blood Pressure Study. JAMA 1990;264:354-358.

47. Julius S. Mejia A, Jones K, et al. "White coat" versus "sustained" borderline hypertension in Tecumseh, Michigan. Hypertension 1990;16:617-623.

48. Pfeifle B, Ditschuneit H. Effect of insulin on the growth of cultured arterial smooth muscle cells. Diabetologia 1981;20: 155-158.

49. Stout RW, Bierman EL, Ross R. Effect of insulin on the proliferation of cultured primate arterial smooth muscle cells. Circ Res 1975;36:319-327.

50. Pfeifle B, Ditschuneit HH, Ditschuneit H. Insulin as a cellular growth regulator of rat arterial smooth muscle cells in vitro. Horm Metab Res 1980;12:381-385.

51. Welborn TA, Wearne $\mathrm{K}$. Coronary heart disease incidence and cardiovascular mortality in Busselton with reference to glucose and insulin concentrations. Diabetes Care 1979;2: $154-160$.

52. Ducimetiere P, Eschwege E, Papoz L., Richard JL, Claude $\mathrm{JR}$, Rosselin G. Relationship of plasma insulin levels to the incidence of myocardial infarction and coronary heart disease mortality in a middle-aged population. Diabetologia 1980;19:205-210.

53. Pyorala K, Savolainen E, Kaukola S. Haapakoski J. Plasma insulin as a coronary heart disease risk factor: Relationship to other risk factors and predictive value during $91 / 2$ year follow-up of the Helsinki Policemen Study population. Acta Med Scand Suppl 1985;701:38-52.

54. DeFronzo RA, Ferrannini E. Insulin resistance: A multifaceted syndrome responsible for NIDDM, obesity, hypertension, dyslipidemia, and atherosclerotic cardiovascular disease. Diabetes Care 1991;14:173-194.

55. DeFronzo RA, Gunnarsson R, Bjorkman O, Olsson M, Wahren J. Effects of insulin on peripheral and splanchnic glucose metabolism in noninsulin-dependent (type II) diabetes mellitus. $J$ Clin Invest 1985;76:149-155.

56. Natali A, Santoro D, Palombo C, Cerri M, Ghione S, Ferrannini E. Impaired insulin action on skeletal muscle metabolism in essential hypertension. Hypertension 1991:17: $170-178$.

57. Deibert DC, DeFronzo RA. Epinephrine-induced insulin resistance in man. J Clin Invest 1980;65:717-721.

58. Zeman RJ, Ludemann R, Easton TG, Etlinger JD. Slow to fast alterations in skeletal muscle fibers caused by clenbuterol, a beta-2-receptor agonist. Am J Physiol 1988;254: E726-E732.

59. Julius S. Gudbrandsson T. Jamerson K, Shahab ST, Andersson 0 . Hypothesis. The hemodynamic link between insulin resistance and hypertension. $J$ Hypertens 1991;9:983-986.

60. Jamerson KA, Julius $\mathrm{S}$, Gudbrandsson $\mathrm{T}$, Andersson 0 , Brant DO. Reflex sympathetic activation induces acute insulin resistance in the human forearm. Hypertension 1993;21: 886-893.

61. Sullivan JM, Prewitt RL, Josephs JA. Attenuation of the microcirculation in young patients with high-output borderline hypertension. Hypertension 1983;5:844-851.

62. Hartper RN, Moore MA, Marr MC, Watts LE, Hutchins PM. Arteriolar rarefaction in conjunctiva of human essential hypertensives. Microvasc Res 1978;16:369-372.

63. Short DS, Thomson AD. The arteries of the small intestine in systemic hypertension. $J$ Pathol Bacteriol 1959;78:311334.

64. Henrich HA, Romen W, Heimgartner W, Hartung E, Baumer F. Capillary rarefaction characteristic of the skeletal muscle of hypertensive patients. Klin Wochensch 1988; 66:54-60.

65. Tibblin G, Bergentz S-E, Bjure J, Wilhelmsen L. Hematocrit, plasma protein, plasma volume, and viscosity in early hypertensive disease. Am Heart $J$ 1966;72:165-176.

66. Sorlie PD, Garcia-Palmieri MR, Costas R Jr, Havlik RJ. Hematocrit and risk of coronary heart disease: The Puerto Rico Heart Health Program. Am Heart J 1981;101:456-461. 67. Salonen JT, Nyyssonen K, Korpela H, Tuomilehto J, Seppa- 
nen $\mathrm{R}$, Salonen $\mathbf{R}$. High stored iron levels are associated with excess risk of myocardial infarction in eastern Finnish men. Circulation 1992;86:803-811.

68. Julius S, Pascual A, Reilly K, London R. Abnormalities of plasma volume in borderline hypertension. Arch Intern Med 1971;127:116-119.

69. Cohn JN. Relationship of plasma volume changes to resistance and capacitance vessel effects of sympathomimetic amines and angiotensin in man. Clin Sci 1966;30:267-278.

70. Julius S, Pascual AV, Abbrecht P, London R. Effect of beta-adrenergic blockade on plasma volume in human subjects. Proc Soc Exp Biol Med 1972;140:982-985.

71. Kjeldsen SE, Gjesdal K, Eide I, et al. Increased betathromboglobulin in essential hypertension: Interactions between arterial plasma adrenaline, platelet function and blood lipids. Acta Med Scand 1983;213:369-373.

72. Levy D, Garrison RJ, Savage DD, Kannel WB, Castelli WP. Prognostic implications of echocardiographically determined left ventricular mass in the Framingham heart study. $N$ Engl J Med 1990;322:1561-1566.

73. Korner PI, Shaw J, Uther JB, West MJ, McRitchie RJ, Richards JG. Autonomic and nonautonomic circulatory components in essential hypertension in man. Circulation 1973; 48:107-117.

74. Schwartz PJ, Vanoli E, Stramba-Badiale M, Ferrari GM, Billman GE, Foreman RD. Autonomic mechanisms and sudden death - New insights from analysis of baroreceptor reflexes in conscious dogs with and without a myocardial infarction. Circulation 1993;78:969-979.

75. Billman GE. Effect of carbachol and cyclic GMP on susceptibility to ventricular fibrillation. FASEB 1990;4:1668-1673.

76. Simpson P. Norepinephrine-stimulated hypertrophy of cultured rat myocardial cells is an alpha-1 adrenergic response. $J$ Clin Invest 1983;72:732-738.

77. Dzau VJ, Gibbons GH, Pratt RE. Molecular mechanisms of vascular renin-angiotensin system in myointimal hyperplasia. Hypertension 1991;18(Suppl):II100-II105.

78. Vogt M, Motz W, Schwartzkopff B, Strauer B. Coronary microangiopathy and cardiac hypertrophy. Eur Heart $J$ 1990;11(Suppl B):133-138.

79. Egan B, Julius S. Vascular hypertrophy in borderline hypertension: Relationship to blood pressure and sympathetic drive. Clin Exp Hypertens [A] 1985(A7):243-255.

80. MacMahon S, Peto R, Cutler J, et al. Blood pressure, stroke, and coronary heart disease. Part 1, prolonged differences in blood pressure: Prospective observational studies corrected for the regression dilution bias. Lancet 1990;335: 765-774.

81. Collins R, Peto R, MacMahon S, et al. Blood pressure, stroke, and coronary heart disease. Part 2, short-term reduction in blood pressure: Overview of randomised drug trials in their epidemiological context. Lancet 1990;335: 827-838. 